\title{
Substance abuse in Children and adolescent: A Retrospective Study
}

\author{
Singh M. ${ }^{1}$, Bala N. ${ }^{2}$, Garg P.D. ${ }^{3}$, Bansal S. ${ }^{4}$, Bumrah S. ${ }^{5}$, Attri $A^{6}$ \\ ${ }^{1}$ Dr. Manjit Singh, Assistant Professor, ${ }^{2}$ Dr. Neeru Bala, Assistant Professor, ${ }^{3}$ PD Garg, Professor and Head, ${ }^{4}$ Dr. Shivani \\ Bansal, Junior Resident, above all authors are affiliated with Department of Psychiatry, Government Medical College, \\ Amritsar (Punjab), India, ${ }^{5}$ Dr. Sunaina Bumrah, Undergraduate Student, SGRD Medical College, Amritsar (Punjab), \\ India, ${ }^{6}$ Animesh Attri, Undergraduate Student, Thapar University, Patiala (Punjab), India
}

Address for Correspondence: Dr Neeru Bala, Assistant Professor, Department of Psychiatry, Government Medical College, Amritsar (Punjab), India.E-mail - jpattri12@yahoo.co.in

\begin{abstract}
Introduction: Drug addiction among children and adolescents is spreading very fast. The age of initiation of substance use is falling progressively. Aims and Methods: The aim of the study was to know about the socio demographic profile of children and adolescents diagnosed with substance dependence and to assess the pattern of drug dependence. So we conducted a retrospective study in Swami Vivekananda Drug De addiction centre at Amritsar in Punjab. The diagnosis of substance dependence was made by a consultant psychiatrist after direct interview with the patient and the relatives according to International Classification of Diseases (ICD-10). Results: The study comprised 446 children and adolescents who reported for de addiction during the study period. Majority were in the age group 16-19(95.73\%), 49.5\% were from urban areas and $50.5 \%$ patients were from rural areas. Out of these $36.09 \%$ were employed, $24.43 \%$ were unemployed and $39.46 \%$ were students. Our results showed more involvement of male as compared to females. As far as education status is concerned, $47.53 \%$ studied up to matric, $23.99 \%$ up to Secondary school, $12.78 \%$ up to middle, $6.95 \%$ up to primary and $5.38 \%$ were illiterate. Opioids and polysubstance use are common among them. Conclusion: The need of the hour is to educate and counsel young children and adolescents and create awareness among the public regarding drug addiction.
\end{abstract}

Keywords: Adolescence, Opioids, Substance Use, Addiction

\section{Introduction}

Child and adolescent substance use and abuse are highly significant public health problems. The World Health Organization (WHO) defines an adolescent as any person between ages 10 and 19 years. Consumption of illicit substances has increased all over the world and the age of initiation of use is falling progressively [1]. Substance use refers to the use of any psychoactive substances or drugs, which include licit and illicit drugs, other than which are medically indicated [2]. Substance use at a young age is usually associated with a poor prognosis and a lifelong pattern of irresponsible behavior [3]. Youth is a time for maximum experimentation and formation of identity. Use of tobacco, alcohol, and other substances is a problem

Manuscript received: $9^{\text {th }}$ March 2017

Reviewed: $17^{\text {th }}$ March 2017

Author Corrected: $24^{\text {th }}$ March 2017

Accepted for Publication: $31^{\text {st }}$ March 2017 throughout the world and affects many children and adolescents [4]. It is estimated that, in India, by the time most boys reach ninth grade, $50 \%$ of them have tried at least one of the substance of the abuse nature [5]. Influence of peers and close contacts who use substances are usually responsible for initiating their use in others [6].

A Study was conducted on prevalence patterns and familial aspects of substance use among adolescents in North India and it was found that prevalence of substance use was seen in $52.7 \%$ students belonging to age group 19 to 21 years. More prevalence of substance use was found among law students $(76.2 \%)$ followed by the students from Art stream (62.5\%). Among the users alcohol was most commonly used $(53.5 \%)$, followed by smokers $(27.3 \%)$, tobacco chewers $(8.2 \%)$, cannabis 
$(6.8 \%) .49 \%$ of the users were using substances on daily basis, followed by $23 \%$ who were using weekly. About $29.3 \%$ of users had father using any substance [7].

Today no part of world is free from drug addiction. It is fast spreading in each and every corner of world and India is also under the grip of drugs. Increasing population and nuclear system of families in India is also bringing changing patterns in its social and cultural values. It is very fast spreading in younger children and women too. Drug addiction in children impacts the whole family. In spite of being aware of the harmful effects of substance use, adolescents take up this habit.

The modeling of substance use behavior by parents, older siblings, and peers is a critical negative social influence [8]. Other powerful negative influences involve the media exposure that is the modeling of substance use and abuse by celebrities in movies, television, and music videos [9]. It has been found that school social environment that increase student participation, improve relationships and promote a positive school ethos may be associated with reduced drug use while students who are not engaged in school and those who fail academically are more likely to engage in substance use [10].

This requires comprehensive prevention and control programs in schools and the community, targeted toward adolescents and their parents and other family members. Effective measures are required to encourage shaping the attitude of school children toward selfconfidence and adequacy, as also to prevent risk behavior among adolescents [11].

A study was conducted on prevalence and related risk factors of licit and illicit substances use by adolescent students in southern Taiwan. The prevalence of substance use was estimated as follows: alcohol drinking, $70.7 \%$ (boys $75.1 \%$, girls $51.4 \%$ ); tobacco smoking, $56 \%$ (boys $61.8 \%$, girls $30.2 \%$ ); illicit drug use $6.4 \%$ (boys $6.6 \%$, girls $5.6 \%$ ). Significant risk factors that emerged as common correlates with substances use were behaviour problems, non-negative attitude toward parent's substance use, and peer influence [12].

A Study was conducted on drug dependence in adolescents in north India and it was found that many adolescents came from nuclear family $(63.5 \%)$, of urban background (83.5\%) and were school dropouts $(54.1 \%)$.
Mean age-at-first-use of the primary substance was 14.8 $\mathrm{yr}$ and mean age at first presentation was $17 \mathrm{yr}$. The commonest used primary class of substance was opioids (76.2\%) and the commonest used opioid was heroin $(36.5 \%)$. More than half of the subjects $(54.2 \%)$ were also nicotine dependent at the time of presentation.

The most common reason for starting the use of drugs was curiosity $(78.8 \%)$. About one-fifth $(21.2 \%)$ of the subjects indulged in high-risk behaviour such as having sexual intercourse with multiple sexual partners. Nearly half of the subjects had positive family history of either drug dependence $(40.2 \%)$ or psychiatric disorder $(5.5 \%)$ [13]. A study conducted in united states of America shows that heroin use in adolescents is showing increasing trend [14].

\section{Aim and objectives}

1. To study the socio demographic profile of children and adolescents with substance dependence.

2. To assess the pattern of drug dependence.

\section{Material and Method}

A retrospective study was conducted at Swami Vivekananda Drug De addiction and Treatment Centre (SVNDDTC) of the Department of Psychiatry at the Government Medical College, Amritsar. The study protocol was approved by the Institutional Ethical Committee. Informed written consent was obtained from the patients prior to study as a routine procedure of the centre.

The study population comprised all children and adolescent patients who were registered in Swami Vivekananda Drug De-addiction and Treatment Centre (SVNDDTC), department of Psychiatry, Government Medical College Amritsar, during the study period (January 2013 to December 2015). The diagnosis of substance dependence was made by a consultant psychiatrist according to International Classification of Diseases (ICD-10) after direct interview with the patient and the relatives.

For all the registered subjects the available records were scanned and relevant information was retrieved according to a study specific predetermined coding plan. The information included was socio-demographic profile and substance use pattern. The clinical information was discerned from the recorded history and clinical evaluation. 
Excluded population- Patients with mental retardation or organic brain syndrome (both determined by a clinical interview and examination by a qualified psychiatrist), or those who refused to give informed consent were excluded. None of the patients reported in this study were part of the previously published study from our centre.

Measures- An appropriate proforma was to used to record age, sex, education, occupation, religion and locality. This will include details of substances abused by the participants. Descriptive statistics were used for the demographic and clinical variables. Diagnosis of substance dependence was made according to the ICD10 Criteria.

Statistical analysis: The data was evaluated using Microsoft Office Excel worksheet and percentage and proportions for every variable was calculated.

\section{Results}

Demographic profile- Total of 446 children and adolescents reported for de addiction during the study period from January 2013 to December 2015.Distribution among age group has been divided into two groups age 10-15and age 1619.Majority were in the age group 16-19(95.73\%). (Table 1)

Table 1: Distribution among Age group.

\begin{tabular}{|c|c|c|}
\hline Year & Age 10-15 Years & Age 16-19 Years \\
\hline 2013 & 4 & 160 \\
\hline 2014 & 9 & 177 \\
\hline 2015 & 6 & 90 \\
\hline
\end{tabular}

The patients from urban areas were $49.5 \%$ and $50.5 \%$ patients were from rural areas.(table2).Out of these $36.09 \%$ were employed, $49.46 \%$ were unemployed and $14.43 \%$ were students. Majority were Sikh by religion, $47.53 \%$ studied up to matric, $23.99 \%$ up to secondary school, $12.78 \%$ up to middle, $6.95 \%$ up to primary and $5.38 \%$ were illiterate. Males were $99.77 \%$ and $0.22 \%$ females

Table 2: Distribution among Rural and Urban Patients.

\begin{tabular}{|c|c|c|}
\hline Year & Rural & Urban \\
\hline 2013 & 91 & 73 \\
\hline 2014 & 91 & 95 \\
\hline 2015 & 43 & 53 \\
\hline
\end{tabular}

Clinical profile -The most common substance of abuse was heroin and other opioids (58.74\%). Others were tobacco used by chewing or smoking or both, alcohol, cannabinoids, inhalants. About 35.6\% were polysubstance users and out of these $8.74 \%$ were having polysubstance $>2$ (Figure 1).Majority were non injection drug users (67.26\%) and $32.74 \%$ patients were taking drugs by injection route. Out of the patients taking opioids $44.6 \%$ were put on agonist treatment that is bupernorphine and majority were put on detoxification treatment. The reasons for initiating substance use were peer pressure $(68 \%)$, curiosity (12\%) and frustration or stress $(20 \%)$. The reasons for abuse were withdrawal symptoms (60\%), peer pressure $(37 \%)$ and stress $(3 \%)$.

Table 3: Distribution of different drugs.

\begin{tabular}{|c|c|c|}
\hline Drugs & Number & Percent \\
\hline Heroin or ther opiods & 262 & 58.74 \\
\hline Alcohol & 3 & 0.67 \\
\hline Cannabinoids & 8 & 1.79 \\
\hline Tobacco & 14 & 3.14 \\
\hline Inhalants & 1 & 0.22 \\
\hline Poly substance $<2$ & 120 & 26.91 \\
\hline Poly substance $>2$ & 38 & 8.52 \\
\hline
\end{tabular}




\section{Discussion}

The incidence of drug abuse among children and adolescents is higher than the general population. Heroin, Opium, Alcohol, Cannabis and Propoxyphene are the five most common drugs being abused by children in India. In India an NGO survey revealed that $63.6 \%$ of patients coming in for treatment were introduced to drugs at a young age below 15 years. This is notably because youth is a time for experimentation and identity forming. In developed countries drug abuse among youth is generally associated with particular youth subcultures and lifestyles. According to another report $13.1 \%$ of the people involved in drug and substance abuse in India, are below 20 years. A survey shows that of all alcohol, cannabis and opium users $21 \%, 3 \%$ and $0.1 \%$ are below the age of eighteen [15].

Substance abuse disorder is among the leading public health problems in modern day world as they cause a lot of human suffering in terms of morbidity, mortality and economic loss. Majority of the patients were Sikh by religion as the study was conducted in Punjab and the state caters to a large number of Sikh population. The substance abuse was more common in males in the study as compared to females as seen in earlier studies conducted in north India [16]. Also the research included only those patients seeking treatment at the de addiction centre, many females do not report or seek treatment because of pressure of society or stigma attached with it. The commonest substance of abuse recorded was opioids in our study and among opioids most common was heroin. It is supportive of earlier studies [17]. The most common reason for initiating substance use was peer pressure which is supportive of earlier studies $[6,8]$. It has also been seen in the study that number of patients have increased over the years and this indirectly indicates that problem of drug abuse is rising among the youth. This is in accordance with the earlier study conducted in north India [13]. Varma et al [18] found that rates of current use of alcohol in Punjab were $45.9 \%$ in Jalandhar and $27.7 \%$ in Chandigarh whereas it was $28.1 \%$ in rural areas of Punjab [19]. Shukla [20] reported that $38.3 \%$ of the rural population in Uttar Pradesh was habitual substance users. In a study conducted in rural community in Bihar prevalence of alcohol/drug use was found to be $28.8 \%$ of the study population [21]. The picture is grim if the world statistics on the drugs scenario is taken into account .With a turnover of around $\$ 500$ billions, it is the third largest business in the world, next to petroleum and arms trade. About 190 million people all over the world consume one drug or the other $[22,23]$

Suggestions: There is an utmost need to educate and counsel young students and adolescents regarding harmful effects of substance use. Health education may be imparted by inclusion of this topic in the school curriculum. Parents should also be educated on discouragement of substance use and on taking proper care of their children.

Limitations: The result of our study must be seen within its limitations. The retrospective chart review entailed inferring relevant data from the recorded narratives. The sample comprised of children and adolescents seeking de addiction treatment at one centre. Hence, generalization of our findings to other de addiction centres and across the community and the country demands caution.

However within these limitations the study leads to the following conclusions. The children and adolescents seeking treatment for substance abuse were mostly in the age group of $16-19$, majority males almost equally distributed among urban and rural areas and majority studied up to matric. The most common substance of abuse was heroin or other opioids impacting their lives and their family. This study may help us in understanding a rapidly increasing public health problem which is of national importance and for suggesting probable solutions for reducing this problem.

Understanding socio demographic and behavioral aspects of substance users will be helpful in reducing the risk which is caused due to substance use in the potential loss of lives of children and adolescents and their careers and also to their families and society in general.

\section{Funding: Nil, Conflict of interest: None Permission of IRB: Yes}

\section{References}

1. UNDCP World Drug Report. New York; Oxford University press Inc.; 1997. Downloaded date 06-032017.

2. Smart RG, Hughes PH, Johnston LD, Anumonye A, Khant U, Medina Mora ME et al. A methodology for 
student drug-use surveys. Geneva: World Health Organization. 1980

3. Tripathi BM, Lal R. Substance abuse in children and adolescents Indian J Pediatr 1999 Jul-Aug;66(4): 569-75.

4. WHO study group on drug dependence. WHO Tech Rep Ser No 407. 1969:6-8.

5. Ramachandran V. The prevention of alcohol-related problems. Indian J Psychiatry. 1991 Jan;33 (1):3-10.

6. Bala N, Kaur G, Attri JP, Singh M, Thakur M, Jain P. Psychiatric and anesthetic implications of substance abuse: Present scenario. Anesth Essays Res. 2015 SepDec;9(3):304-9. doi: 10.4103/0259-1162.161810.

7. Gupta S, Singh SS, Kumar D, Kaur T, and Arora S. Prevalence, Pattern and Familial Effects of Substance Use Among the Male College Students -A North Indian Study. J Clin Diagn Res 2013 Aug; 7(8): 1632-1636.

8. Mayberry ML, Espelage DL, Koenig B. Multilevel modeling of direct effects and interactions of peers, parents, school, and community influences on adolescent substance use. J Youth Adolesc. 2009 Sep; 38 (8):1038-49. doi: 10.1007/s10964-009-9425-9. Epub 2009 Jun 12.

9. Villani S. Impact of media on children and adolescents: A 10-year review of the research. J Am Acad Child Adolesc Psychiatry. 2001;40:392-401.

10. Fletcher A, Bonell C, Hargreaves J. School effects on young people's drug use: A systematic review of intervention and observational studies. J Adolesc Health. 2008 Mar; 42(3): 209-20. doi: 10.1016/j. jadohealth. 2007. 09.020. Epub 2007 Dec 26.

11. Tsering D, Pal R, Dasgupta A. Substance use among adolescent high school students in India; A survey of knowledge, attitude and opinion. J Pharm Bioallied Sci. 2010 Apr-Jun; 2(2): 137-140. doi: 10.4103/0975-7406. 67005 .

12. Yang MS, Yang MJ, Liu YH, Ko YC. Prevalence and related risk factors of licit and illicit substances use by adolescent students in southern Taiwan. Public health.1998 Sep;112(5):347-52.

13. Saluja BS, Grover S, Irpati AS, Mattoo SK, Basu D. Drug dependence in adolescents. 1978-2003: a clinicalbased observation from North India. Indian $\mathrm{J}$ Pediatr. 2007 May;74(5):455-8.

14. Schwartz RH. Adolescent heroin use: a review. Pediatrics. 1998 Dec;102(6):1461-6.

15. CHILD Protection \& Child Rights. Available from http://www.childlineindia.org.in/children-affected-bysubstance-abuse.htm. Downloaded date 13/04/2017

16. Tufeel AB, Abdul MG, Syed SQ, Mushtaq AM, Gazi MI, Zahid AK. An epidemiological study on substance abuse among college students of north India (Kashmir valley). Int $\mathrm{j}$ med sci public health 2013; 2(3):562-567.

17. Sung HE, Richter L, Vaughan R, Johnson P, Thom B. Nonmedical use of prescription opioids among teenagers in the United States: Trends and correlates. J Adol Hlth. 2005;37:44-51

18. Varma VK, Singh A, Singh S, Malhotra AK. Extent and pattern of alcohol use in North India. Indian $\mathbf{J}$ Psychiatry 1980; 22:331-7.

19. Lal B, Singh G. Alcohol consumption in Punjab. Indian J Psychiatry 1978; 20:212-6. 20.Shukla BR. Drinks and drugs in a north Indian village-an anthropological study. Ethnographic and Folk culture Society: Lucknow, India; 1979.

21. Jena R, Shukla TR, Hemraj P. Drug abuse in a rural community in Bihar: Some psychosocial correlates. Indian J Psychiatry 1996; 38:43-6.

22. Miller, WR. Sanchez, VC. Motivating young adults for treatment and lifestyle change. In: Howard G., editor. Issues in alcohol use and misuse in young adults. University of Notre Dame Press; 1993. pp. 55-82.

23. Ahmad N, Bano R, Agarwal VK, Kalakoti P. Substance abuse in India.Pravara MedRev2009;1(4):4-6

\section{How to cite this article?}

Singh M, Bala N, Garg P.D, Bansal S, Bumrah S, Attri A. Substance abuse in Children and adolescent: A Retrospective Study. Int J Med Res Rev 2017;5(03):352-356 doi:10.17511/ijmrr. 2017.i03.22. 